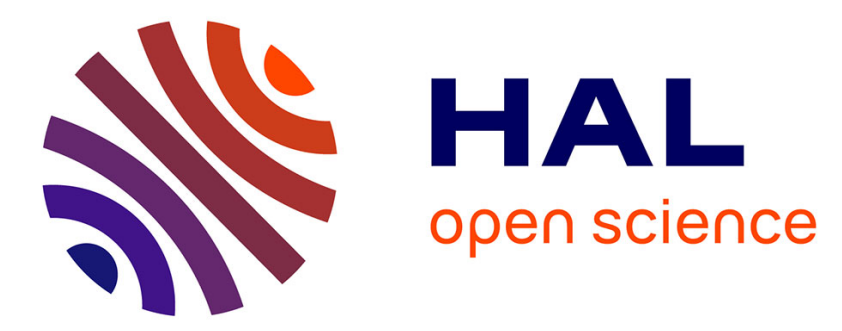

\title{
Zinc-Azatrane Complexes as Efficient Catalysts for the Conversion of Carbon Dioxide into Cyclic Carbonates
}

Benjamin Bousquet, Alexandre Martinez, Véronique Dufaud

\section{To cite this version:}

Benjamin Bousquet, Alexandre Martinez, Véronique Dufaud. Zinc-Azatrane Complexes as Efficient Catalysts for the Conversion of Carbon Dioxide into Cyclic Carbonates. ChemCatChem, 2018, 10 (4), pp.843-848. 10.1002/cctc.201701481 . hal-02091940

\section{HAL Id: hal-02091940 https://hal.science/hal-02091940}

Submitted on 6 Apr 2019

HAL is a multi-disciplinary open access archive for the deposit and dissemination of scientific research documents, whether they are published or not. The documents may come from teaching and research institutions in France or abroad, or from public or private research centers.
L'archive ouverte pluridisciplinaire HAL, est destinée au dépôt et à la diffusion de documents scientifiques de niveau recherche, publiés ou non, émanant des établissements d'enseignement et de recherche français ou étrangers, des laboratoires publics ou privés. 


\title{
Zinc-Azatrane Complexes as Efficient Catalysts for the Conversion of Carbon Dioxide into Cyclic Carbonates
}

\author{
Benjamin Bousquet, ${ }^{[a]}$ Alexandre Martinez, ${ }^{*[b]}$ and Véronique Dufaud ${ }^{*[a]}$
}

Three $\mathrm{Zn}$ complexes based on the $\mathrm{N}_{4}$-tris(2-aminoethyl)amine (tren) chelating ligand and presenting a $C_{3}$-symmetrical axis were synthesized and successfully applied in the coupling of $\mathrm{CO}_{2}$ with terminal and internal epoxides. These complexes proved to be efficient catalysts if associated with tetrabutylammonium iodide, even at a low catalyst loading $(0.005 \mathrm{~mol} \%)$ or at room temperature, and allowed the production of cyclic carbonates in good to high yields. Variation of the substitution pattern on the tren ligand was shown to impact the catalyst performance greatly, and the highest turnover number (TON) (up to 11200 ) was achieved with the less sterically hindered methyl-substituted Zn"-azatrane complex. These binary Znazatrane/ $\mathrm{NBu}_{4}$ l catalytic systems could be applied to a wide range of epoxide substrates, including the more challenging internal epoxides. Moreover, although soluble in the reaction medium, $\mathrm{Zn}$-azatrane catalysts could be easily recovered and reused up to three times without any substantial loss in activity, proving their robustness under the reaction conditions.

\section{Introduction}

The development of catalytic processes that can control the outcome of a reaction continues to arouse interest from both academia and industry. ${ }^{[1]}$ Examination of the huge number of existing coordination complexes capable of catalyzing organic transformations in a highly efficient and selective way has revealed some privileged structures, ${ }^{[2,3]}$ including Schiff base, ${ }^{[4,5]}$ porphyrine- $-{ }^{[6,7]}$ and phosphoramidite-derived ${ }^{[8]}$ complexes, that have been successfully applied in numerous reactions. ${ }^{[1]}$ Among them, the conversion of carbon dioxide $\left(\mathrm{CO}_{2}\right)$ into cyclic carbonates by coupling with epoxides ${ }^{[9-12]}$ has emerged as a powerful tool to produce renewable chemicals from this greenhouse gas: indeed $\mathrm{CO}_{2}$ is abundant, cheap, and nontoxic, and as such, it represents an ideal $C_{1}$ building block for the development of greener and safer alternatives to fossil-fuel-based resources and phosgene-based organic transformations. ${ }^{[13,14]}$ Nevertheless, the discovery of catalysts capable of converting carbon dioxide into fine chemical products, under mild operating temperatures and pressures, remains challenging because of its kinetic and thermodynamic stability. In general, active catalytic systems for this reaction involve the use of a metal complex in conjunction with a nucleophile, usually a halide anion, that can be either included within the same structure (monocomponent catalyst) ${ }^{[15,16]}$ or added separately (bicompo- nent catalyst $)^{[17,18]}$ during the catalytic reaction. In all of these catalytic systems, the metal-derived complex (the Lewis acid) and the nucleophile act cooperatively at the epoxide through oxygen-atom coordination and nucleophile ring opening, respectively. Some of the ligand scaffolds mentioned above have been used to build up transition-metal-based catalysts to incorporate $\mathrm{CO}_{2}$ efficiently into cyclic carbonates. The most performing ligand-metal configurations include $\mathrm{N}_{4}$-porphyrins, ${ }^{[19-22]} \mathrm{N}_{4}$-Schiff bases, ${ }^{[23,24]} \mathrm{N}_{2} \mathrm{O}_{2}$-salen/salphen, ${ }^{[25-28]}$ and $\mathrm{N}_{2} \mathrm{O}-$ substituted phenols ${ }^{[2,30]}$ associated with $\mathrm{Al}, \mathrm{Co}, \mathrm{Fe}, \mathrm{Mg}$, and $\mathrm{Zn}$ metals, amongst others. For instance, North et al. described the use of a very active bimetallic aluminum salen complex, either homogeneous ${ }^{[31,32]}$ or attached to a silica surface through ammonium linkages, ${ }^{[33]}$ that was able to operate at room temperature and atmospheric pressure of $\mathrm{CO}_{2}$. Of particular interest to the present report are a series of studies by Kleij et al. ${ }^{[34,35]}$ on aluminum-aminotriphenolate- and vanadium-aminotriphenolate-based complexes, which showed unprecedented high activity if used in conjunction with tetrabutylammonium halide salts. These catalysts are structurally very similar in terms of geometry to the $C_{3}$ tris(2-aminoethyl)amine (tren) ligand coordinated to zinc, which forms the core of the catalyst system we report here. Indeed, tren derivatives are particularly attractive, as upon complexation with a metal or a heteroelement $(B, P, G a$.) they can lead to azatrane structures, a well-known class of compounds that present unique features. ${ }^{[36,37]}$ The tren ligands usually bind in a tetradentate manner, involving both $\mathrm{N}_{3}$ chelation of the aminoethyl moieties and coordination of the fourth neutral nitrogen donor atom in the apical position (Scheme 1). The simultaneous formation of three five-membered rings provides thermodynamic stability to the whole structure, thereby creating a sterically protected, threefold-symmetric "pocket" around the central element. In addition, the electronic and steric properties can 


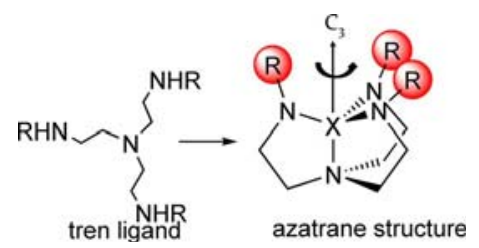

Scheme 1. Representation of the azatrane structure.

also be easily tuned notably by changing the auxiliary groups on the equatorial nitrogen atoms, thus allowing one to test for structure-activity relationships.

We recently reported on the use of azaphosphatrane (AZAP) structures as single-component organocatalysts for the coupling of $\mathrm{CO}_{2}$ with various epoxides. ${ }^{[38,39]}$ Although purely organic catalysts generally require elevated temperatures and pressures to achieve sufficient conversion, the azaphosphatrane catalysts were able to operate at atmospheric pressure of $\mathrm{CO}_{2}$ and a low catalyst loading $(0.1 \mathrm{~mol} \%)$ without the need for an additional co-catalyst or additives. Mechanistic insight based on kinetic studies showed that dual activation of both the epoxide and $\mathrm{CO}_{2}$ took place at the same azaphosphatrane molecule, which was further supported by encapsulating the active site of AZAP in a hemicryptophane structure. ${ }^{[40]}$ Despite these promising results, it appears that this class of ligands has been underexploited, and no catalyst based on a metal-azatrane structure has been described for the conversion of $\mathrm{CO}_{2}$ into cyclic carbonates.

Herein, we wish to report on the synthesis and characteriza-

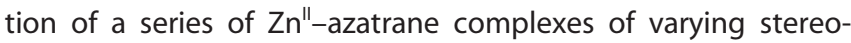
electronic properties and their utilization in the coupling of $\mathrm{CO}_{2}$ with epoxides. In addition to being inexpensive and biorelevant, several $\mathrm{Zn}$ complexes bearing $\mathrm{N}_{2} \mathrm{O}_{2}$ ligands, ${ }^{[26,27,41]}$ and two examples with $\mathrm{N}_{4}$-donor ligands, ${ }^{[42,43]}$ have already proven their efficiency for the production of organic carbonates. To the best of our knowledge, no examples of a $C_{3}$-symmetric $\mathrm{N}_{4}$ chelated $\mathrm{Zn}$ complex have been reported for this transformation.

As we shall see, $\mathrm{Zn}$ "-azatrane complexes in conjunction with tetrabutylammonium iodide led to the formation of cyclic carbonates in good to high yields. These catalytic systems were still found to be active even at a low catalyst loading (0.005\%) or at room temperature, providing high turnover numbers. Structure-activity relationships were evidenced, and the less sterically hindered $Z \mathrm{n}^{\prime \prime}$-azatrane catalyst was the most active. These $\mathrm{Zn}$ catalysts could be reused up to three times without any noticeable loss in activity, showing high stability under the reaction conditions.

\section{Results and Discussion}

Three N-substituted Zn"-azatrane complexes bearing methyl (see compound $\mathbf{2 a}$ ), p-methoxybenzyl (see compound $\mathbf{2}$ b), and neopentyl (see compound $\mathbf{2 c}$ ) groups were readily prepared by mixing corresponding tren ligands $1 \mathrm{a}-\mathrm{c}$ with 1 equivalent of the $\mathrm{Zn}\left(\mathrm{ClO}_{4}\right)_{2}$ salt in $\mathrm{MeOH}$ at room temperature for $1 \mathrm{~h}$ in the presence of a catalytic amount of triethyla-

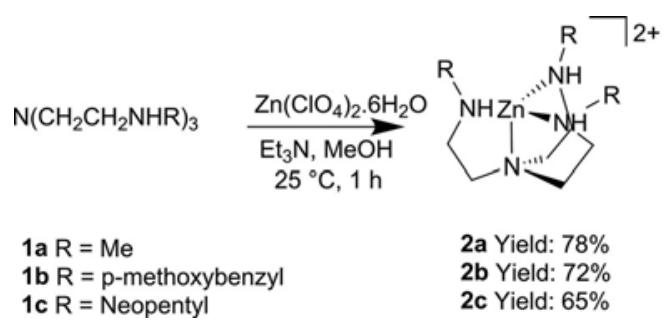

$2 \mathrm{ClO}_{4}$

$\begin{array}{ll}\text { 1a } R=\text { Me } & \text { 2a Yield: } 78 \% \\ \text { 1b } R=p \text {-methoxybenzyl } & \text { 2b Yield: } 72 \% \\ \text { 1c } R=\text { Neopentyl } & \text { 2c Yield: } 65 \%\end{array}$

Scheme 2. Synthesis of $Z n^{\prime \prime}$-azatrane complexes $\mathbf{2}$ a-c.

mine, as shown in Scheme 2. Complexes $\mathbf{2} \mathbf{a}-\mathbf{c}$ were isolated in good yields (65-78\%) and were fully characterized by NMR spectroscopy $\left({ }^{1} \mathrm{H}\right.$ and ${ }^{13} \mathrm{C}$ ) and HRMS analyses (see the Experimental Section). The ${ }^{1} \mathrm{H}$ NMR spectra of the tren ligands after complexation to the $\mathrm{Zn}$ center reveal the equivalence of the substituents on the three equatorial nitrogen atoms, as illustrated for complex 2 a (Figure S1, Supporting Information). This suggests that all the $Z \mathrm{n}^{\text {"l}}$-azatrane complexes feature $C_{3}$ symmetry in solution with respect to the NMR timescale. HRMS analyses indicate a $\left[\mathrm{M}-2 \mathrm{ClO}_{4}+\mathrm{Cl}\right]^{+}$molecular fragment for all complexes $2 \mathrm{a}-\mathrm{c}$. The presence of chloride ions could stem either from partial decomposition of the $\mathrm{ClO}_{4}^{-}$anion during analysis or from trace amounts of the chlorine anion present in the spectrometer, which could subsequently coordinate to the Zn center.

In a first series of experiments, screening of the reaction parameters was undertaken to delineate the optimal conditions for the $\mathrm{Zn}$ "-azatrane complexes to function efficiently. The coupling of 1,2-epoxyhexane with $\mathrm{CO}_{2}$ to produce 1-hexene carbonate (EC) was chosen as a benchmark reaction, and $2 \mathrm{a}$ was first evaluated in combination with tetrabutylammonium iodide $\left(n \mathrm{Bu}_{4} \mathrm{NI}\right)$ as a co-catalyst in neat substrate under the following conditions: $2 \mathrm{a}(0.25 \mathrm{~mol} \%), n \mathrm{Bu}_{4} \mathrm{NI}(0.4 \mathrm{~mol} \%), 110^{\circ} \mathrm{C}$, and $\mathrm{CO}_{2}$ (10 bar, $\left.1 \mathrm{bar}=0.1 \mathrm{MPa}\right)$. In all of the cases studied, complete selectivity towards the cyclic carbonate was observed. Detailed catalytic protocols and analyses of the crude mixtures by ${ }^{1} \mathrm{H}$ NMR spectroscopy (Figure S2) are displayed in the Experimental Section and Supporting Information, respectively. The time-dependent reaction profile of $2 \mathrm{a}$ is provided in Figure S3. One can see that the reaction with 2 a proceeded rapidly, achieving up to $79 \%$ yield ${ }^{1}$ in EC after $3 \mathrm{~h}$ and full conversion after $6 \mathrm{~h}$. To allow for the observation of subtle effects among the different $\mathrm{Zn}^{\prime \prime}$-azatrane catalysts, the other parameters were assessed using a time of $3 \mathrm{~h}$, as this time period allowed sufficient and differentiable conversion of the 1,2-epoxyhexane substrate. The effect of the reaction temperature on the catalytic performance of $\mathbf{2}$ a was then investigated, as the temperature can impact both the reaction rate and the solubility of $\mathrm{CO}_{2}$ in the reaction medium. The results shown in Figure $\mathrm{S} 4$ reveal that the reaction temperature strongly affected the catalyst reactivity, as only a trace amount of the EC prod-

\footnotetext{
All yields in this article were determined by integration of clearly identified product signals in the NMR spectrum in the presence of an internal standard (mesitylene). For protocols for the purification of cyclic carbonates at the gram scale, see Luis Martínez-Rodríguez et al. ${ }^{[46]}$
} 
uct was detected at $50^{\circ} \mathrm{C}$, whereas increasing the temperature from 80 to $130^{\circ} \mathrm{C}$ led to a marked increase in the yield of EC with nearly full conversion at $130^{\circ} \mathrm{C}$. As working at too high a temperature involves a high energy input, which is not attractive from a green perspective, $110^{\circ} \mathrm{C}$ was considered as a suitable reaction temperature with the production of 1-hexene carbonate in $79 \%$ yield after $3 \mathrm{~h}$. The activation energy for EC formation derived from the kinetic data at variable temperatures (Figure S5) was found to be $(43 \pm 4.2) \mathrm{kJ} \mathrm{mol}^{-1}$, which compares well with the values reported in the literature for the coupling of $\mathrm{CO}_{2}$ with various epoxides by using $\mathrm{Zn}^{[44]}$ and other metal ${ }^{[45]}$ complexes. The pressure of $\mathrm{CO}_{2}$ is also a key parameter to explore, as it may dramatically impact the conversion of epoxides into cyclic carbonates. As shown in Figure S6, our catalytic system, $2 \mathrm{a} / \mathrm{nBu}_{4} \mathrm{Nl}$, exhibited no activity at 1 bar of $\mathrm{CO}_{2}$, as only a trace amount of the EC product was detected by ${ }^{1} \mathrm{H}$ NMR spectroscopy. However, increasing the $\mathrm{CO}_{2}$ pressure further to 5 and 10 bar led to a steady increase in the EC yield up to a maximum of $79 \%$ at 10 bar, after which the yield decreased slightly with increasing pressure. Thus, a pressure of 10 bar seemed to be ideal for $\mathbf{2 a}$ to operate efficiently. If binary catalysts are at stake, another parameter that may affect reactivity is the relative molar ratio between the two catalyst components. Figure S7 shows the dependence of the EC yield on the concentration of the $n \mathrm{Bu}_{4} \mathrm{Nl}$ co-catalyst while keeping the concentration of catalyst $2 \mathrm{a}(0.25 \mathrm{~mol} \%)$ constant. Using a 1:1 molar ratio of $2 \mathrm{a} / \mathrm{nBu}_{4} \mathrm{NI}$ led to poor activity with an EC product yield of only $9 \%$ after $3 \mathrm{~h}$. However, increasing the amount of $n \mathrm{Bu}_{4} \mathrm{Nl}$ slightly from 1 to 1.6 equivalents with respect to $\mathbf{2}$ a significantly impacted the reaction, and a yield of $79 \%$ was attained within the same timeframe. Increasing the quantity of the $n \mathrm{Bu}_{4} \mathrm{NI}$ co-catalyst further to 2 and 3 equivalents led to additional improvements in activity, achieving 87 and $95 \%$ yield, respectively.

The nature of the nucleophile is also a crucial parameter to consider, as it is involved in the first step of the catalytic cycle, that is, opening of the epoxide ring. To investigate the effect of the halide anion of the ammonium salt co-catalyst, we chose to use a 1:1.6 molar ratio of $2 \mathrm{a} / \mathrm{nBu}_{4} \mathrm{NX}$ under the previously optimized conditions to differentiate minor reactivity changes between the binary catalytic systems. The results are displayed in Table 1.

\begin{tabular}{|c|c|c|c|}
\hline Entry & Catalyst & Co-catalyst & $\begin{array}{l}\text { Yield } \\
{[\%]}\end{array}$ \\
\hline 1 & $2 a$ & - & 0 \\
\hline 2 & - & $n \mathrm{Bu}_{4} \mathrm{NI}$ & 20 \\
\hline 3 & - & $n \mathrm{Bu}_{4} \mathrm{NBr}$ & 12 \\
\hline 4 & - & $n \mathrm{Bu}_{4} \mathrm{NCl}$ & 16 \\
\hline 5 & $2 a$ & $n \mathrm{Bu}_{4} \mathrm{NI}$ & 79 \\
\hline 6 & $2 a$ & $n \mathrm{Bu}_{4} \mathrm{NBr}$ & 50 \\
\hline 7 & $2 a$ & $n \mathrm{Bu}_{4} \mathrm{NCl}$ & 6 \\
\hline
\end{tabular}

[a] Reaction conditions: 1,2-epoxyhexane $(10 \mathrm{mmol}), \mathrm{CO}_{2}(10 \mathrm{bar}), 110^{\circ} \mathrm{C}$, $3 \mathrm{~h}, 2 \mathrm{a}(0.25 \mathrm{~mol} \%), n B u_{4} \mathrm{NX}(0.4 \mathrm{~mol} \%)$. Yields were determined by ${ }^{1} \mathrm{H}$ NMR spectroscopy by using mesitylene as an internal standard.
Under these conditions, one can see that $\mathbf{2} \mathbf{a}$ alone was not active (Table 1, entry 1 ) and that the reactions performed with the tetrabutylammonium halides but without 2 a proceeded very modestly with yields below $20 \%$ (Table 1, entries 2-4). Contrarily to what was observed with $n \mathrm{Bu}_{4} \mathrm{NI}$, the association of $2 \mathrm{a}$ with $n \mathrm{Bu}_{4} \mathrm{NBr}$ and $n \mathrm{Bu}_{4} \mathrm{NCl}$ resulted in lower yields. These marked differences in reactivity mirror the nucleophilicity and leaving ability of the anions, which is, under solventless conditions, $\mathrm{I}^{-}>\mathrm{Br}^{-}>\mathrm{Cl}^{-}$. Surprisingly, combining $2 \mathrm{a}$ with $n \mathrm{Bu}_{4} \mathrm{NCl}$ gave rise to a decrease in the yield with respect to the corresponding ammonium used alone (6 vs. $16 \%$ yield), whereas a significant gain in activity was observed in the other cases. The interaction between the chlorine anion (hard Lewis base) and the zinc catalyst (hard Lewis acid) could account for the decrease in activity of this binary system. The $n \mathrm{Bu}_{4} \mathrm{Nl}$ cocatalyst was thus chosen to pursue our catalytic studies, as it showed the highest activity if combined to $\mathbf{2} \mathbf{a}$.

The effect of the substitution patterns of the $\mathrm{Zn}$-azatrane catalysts on the catalytic performance was then investigated by using binary catalytic system $2 \mathrm{a}-\mathrm{c} / \mathrm{nBu}_{4} \mathrm{NI}$ under the optimized conditions. As shown in Table 2 (entries 1-3), Zn"-azatrane complexes bearing $p$-methoxybenzyl (see complex $\mathbf{2} \mathbf{b}$ ) and neopentyl (see complex $2 \mathrm{c}$ ) groups both exhibited lower activity than methyl-substituted complex 2 a (65 vs. $79 \%$ ), but the overall performance of all three $\mathrm{Zn}$-azatrane catalysts at this short reaction time $(3 \mathrm{~h})$ remained very good with turnover numbers (TONs) up to 316 . The gain in activity of approximately $23 \%$ obtained with 2 a $\left(105\right.$ vs. $\left.85 / 87 \mathrm{~h}^{-1}\right)$ could be correlated to the lower steric hindrance of the methyl groups around the $\mathrm{Zn}$ center, thus promoting the coordination and activation of the epoxide at the Lewis acid site. To explore further the structural dependence in terms of catalyst efficiency and to develop more environmentally friendly catalysts, the catalyst and nucleophile loadings were reduced by a factor of 50 to $0.005 \mathrm{~mol} \%$ for $\mathrm{Zn}$-azatranes $\mathbf{2} \mathrm{a}-\mathrm{c}$ and by a factor of 16 to $0.025 \mathrm{~mol} \%$ for $n \mathrm{Bu}_{4} \mathrm{NI}$. Under these low-loading conditions, one can see that $Z n$ catalysts $\mathbf{2} \mathbf{a}-\mathbf{c}$ all exhibited high efficiency and robustness with TONs ranging from 5400 to 11200 after $24 \mathrm{~h}$ of reaction (Table 2, entries 4-6). Notably, $n \mathrm{Bu}_{4} \mathrm{NI}$ alone at a $0.025 \mathrm{~mol} \%$ loading showed very low activity ( $7 \%$ yield; Table 2, entry 7). The best results were obtained with the binary system $2 \mathrm{a} / \mathrm{nBu}_{4} \mathrm{NI}$, the activity of which was approximately twofold higher than that of catalysts $\mathbf{2 ~ b}$ and 2 c (467 vs. $225-250 \mathrm{~h}^{-1}$ ). Here again, the lower steric hindrance around the $\mathrm{Zn}$ catalytic center in $\mathbf{2 a}$ could account for this enhanced reactivity, highlighting the importance of the available space above the Lewis acidic site to synergistically activate the epoxide. Relative to that shown by other $\mathrm{N}_{4}$-chelated $\mathrm{Zn}$ catalysts, $\mathrm{Zn}$-azatrane catalysts $\mathbf{2 a - c}$ showed better performance in the coupling of $\mathrm{CO}_{2}$ with epoxyhexane with, in the case of best catalyst $2 \mathrm{a}$, turnover frequencies (TOFs) on average 47 and 6 times higher than those obtained with $\mathrm{Zn}-\mathrm{bpb}^{[42]}[\mathrm{bpb}=\mathrm{N}, \mathrm{N}$ bis-(2-pyridinecarboxamide)-1,2-benzene, TOF: $10 \mathrm{~h}^{-1}, 80^{\circ} \mathrm{C}$, $20 \mathrm{~h}, 50$ bar, $\left.\mathrm{Zn} / \mathrm{nBu}_{4} \mathrm{NBr}=0.2 / 0.2\right]$ and $\mathrm{Zn}$-pyrrolidine-based catalysts $^{[43]}$ (TOF: $75 \mathrm{~h}^{-1}, 80^{\circ} \mathrm{C}, 20 \mathrm{~h}, 35 \mathrm{bar}, \mathrm{Zn} / \mathrm{nBu}_{4} \mathrm{Nl}=0.005$ / $0.1)$, respectively. The activation of $\mathrm{CO}_{2}$ at room temperature is highly challenging and few catalytic systems are able to ach- 
Table 2. Influence of the structural features of the catalyst on the coupling of $\mathrm{CO}_{2}$ with 1,2 -epoxyhexane by using the 2 a-c/nBu $\mathrm{NI}_{4}$ binary catalytic system. ${ }^{[a]}$

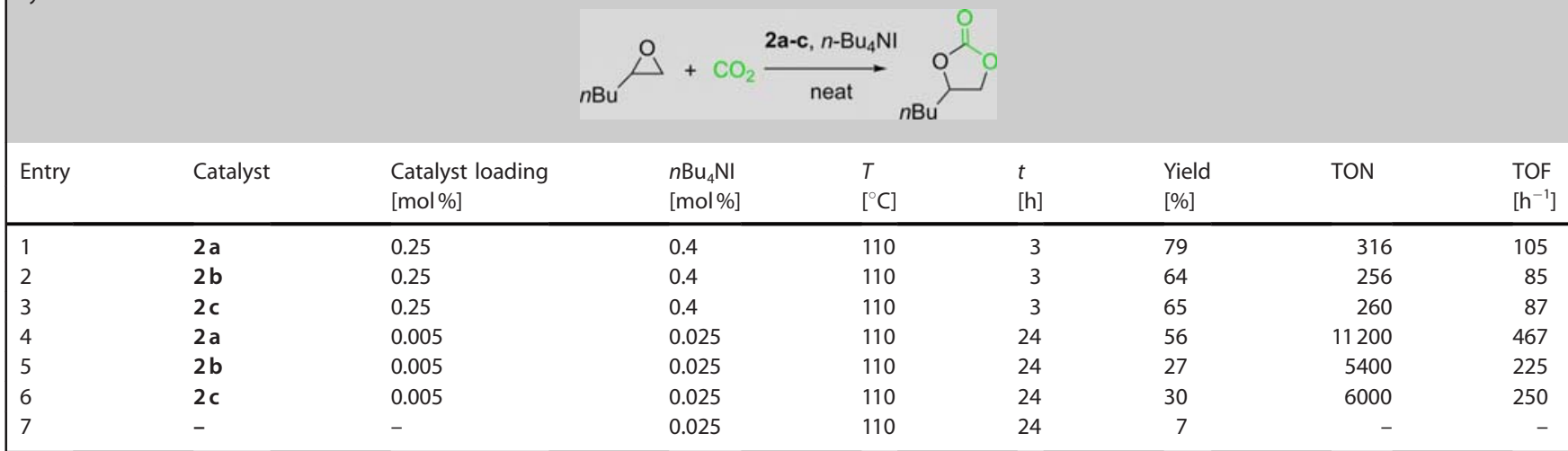

[a] Reaction conditions: 1,2-epoxyhexane (10 mmol), $\mathrm{CO}_{2}$ (10 bar). Yields were determined by ${ }^{1} \mathrm{H}$ NMR spectroscopy by using mesitylene as an internal standard. Turnover number (TON) and turnover frequency (TOF) values are based on the $\mathrm{Zn}$ catalyst.

ieve the conversion of $\mathrm{CO}_{2}$ under such mild conditions. We were pleased to observe that complex 2 a retained some catalytic activity at room temperature to afford the cyclic product in $12 \%$ yield after a period of $24 \mathrm{~h}$ by using the following conditions: 2 a $(2 \mathrm{~mol} \%), n \mathrm{Bu}_{4} \mathrm{NI}(1 \mathrm{~mol} \%), \mathrm{CO}_{2}$ (10 bar), and 1,2epoxyhexane $(10 \mathrm{mmol})$. The activity was much lower with $\mathbf{2} \mathbf{b}$ and 2 c ( 4 and $2 \%$ yield, respectively), underlining the better catalytic efficiency of $\mathbf{2 a}$, in agreement with the results obtained at low loadings (Table 2, entries 4-6).

As $2 \mathrm{a} / n \mathrm{Bu}_{4} \mathrm{Nl}$ appears to be the most efficient system, its applicability to other epoxides was investigated under the optimized conditions. As clearly observed from Table 3, 2 a was applicable to a variety of terminal and internal epoxides, affording exclusively the corresponding cyclic carbonate products in good to high yields. Monosubstituted terminal epoxides were readily converted within a $3 \mathrm{~h}$ timeframe into their related carbonates with yields ranging from 75 to $95 \%$, whereas a longer reaction time ( $24 \mathrm{~h}$ ) was necessary to achieve sufficient conversion for more challenging disubstituted and terminal 1,2epoxy-2-methylpropane ( $55 \%$ yield) and for sterically hindered cyclohexene oxide and cyclopentene oxide ( 23 and $67 \%$ yield, respectively), both obtained with full retention of configuration (cis $>99 \%$ ). Although the reaction conditions reported in the literature are slightly different from ours to provide meaningful comparison, our binary $2 \mathrm{a} / \mathrm{nBu}_{4} \mathrm{NI}$ catalytic system compares favorably with other $\mathrm{N}_{4}$-chelated $\mathrm{Zn}$ catalysts, ${ }^{[42,43]}$ exhibiting, in most cases, greater efficiency for the conversion of terminal and even internal epoxides than the $\mathrm{Zn}-\mathrm{bpb}$ catalyst reported recently by Adolph et al. ${ }^{[42]}$

The reuse of metallic catalysts is also an important issue to investigate from economical and practical use viewpoints. The reusability of $\mathbf{2} \mathbf{a}$ and $\mathbf{2} \mathbf{b}$ was thus examined under the optimized reaction conditions by using 1,2-epoxyhexane as a model substrate over three catalytic cycles. Although homogeneous in nature, azatrane complexes $\mathbf{2} \mathbf{a}$ and $\mathbf{2} \mathbf{b}$ could be readily recovered from the reaction mixture by precipitation in diethyl ether before use in a subsequent run. For each catalytic run, fresh epoxide and the $n \mathrm{Bu}_{4} \mathrm{NI}$ co-catalyst, in the appropriate molar ratio, were introduced in the reactor along with

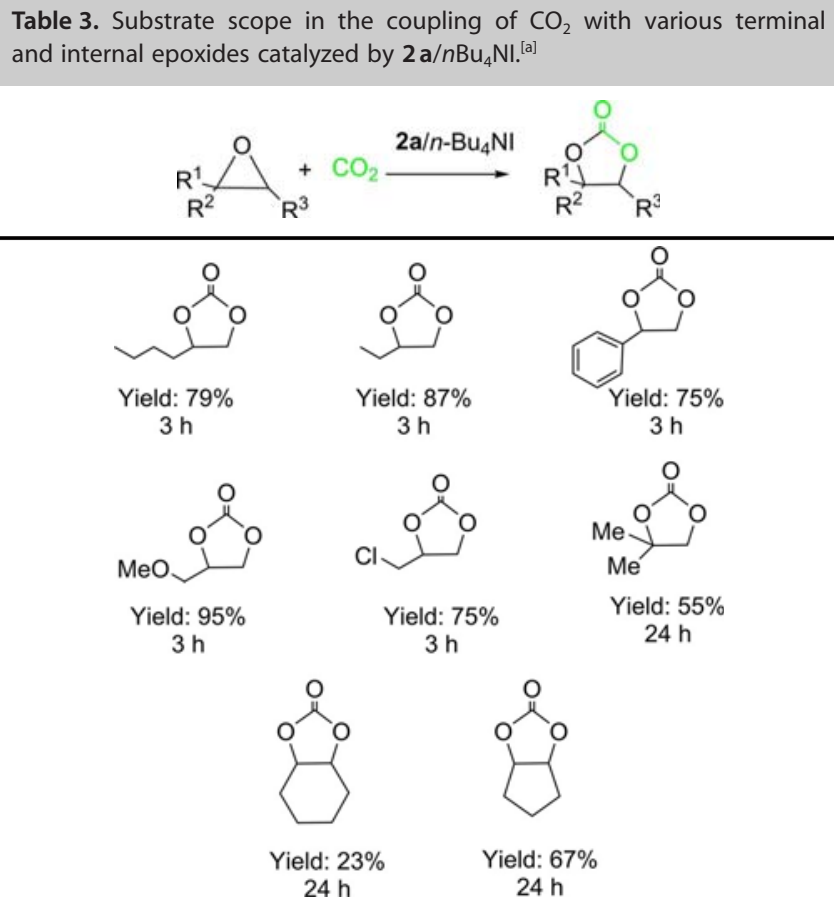

[a] Reaction conditions: epoxide $(10.0 \mathrm{mmol}), 2 \mathrm{a}(0.25 \mathrm{~mol} \%), n \mathrm{Bu}_{4} \mathrm{NI}$ (0.4 mol\%), $110{ }^{\circ} \mathrm{C}, \mathrm{CO}_{2}$ (10 bar). Yields were determined by ${ }^{1} \mathrm{H}$ NMR spectroscopy by using mesitylene as an internal standard.

spent catalyst $\mathbf{2} \mathbf{a}$ or $\mathbf{2} \mathbf{b}$, and the reaction was launched for a duration of $3 \mathrm{~h}$. The yields of the EC product after three repeated runs for both azatrane catalysts are shown in Figure 1. Interestingly, no significant loss in catalytic activity was observed with $\mathbf{2} \mathbf{b}$ over three runs, emphasizing the stability of this catalyst under the reaction conditions and the viability of the recovering method. In the case of $\mathbf{2} \mathbf{a}$, the high initial activity achieved with this catalyst was maintained for the first two cycles, after which a slight decrease was observed. We believe that higher steric hindrance around the $\mathrm{Zn}$ site correlates with catalyst stability by maintaining the azatrane structure intact, thus protecting the Lewis acidic center. 


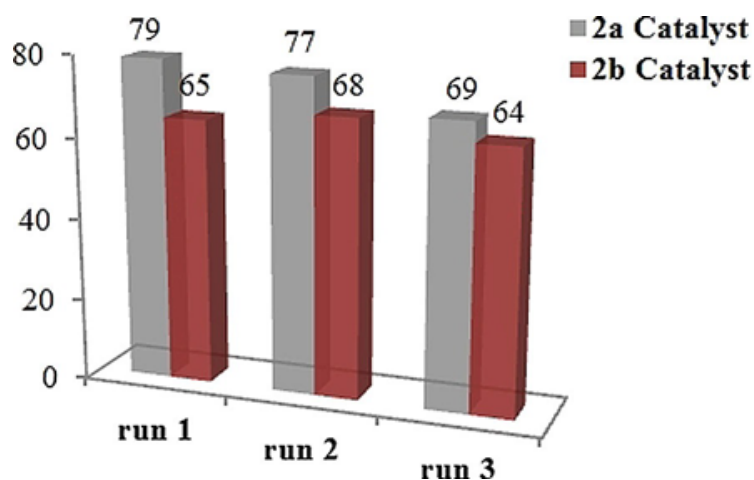

Figure 1. Recyclability of catalysts $\mathbf{2}$ a and $\mathbf{2}$ b after a $3 \mathrm{~h}$ period. Reaction conditions: 1,2-epoxyhexane (10 mmol), catalyst $\mathbf{2}$ a or $\mathbf{2} \mathbf{b}(0.25 \mathrm{~mol} \%)$, $n \mathrm{Bu}_{4} \mathrm{NI}$ co-catalyst $(0.4 \mathrm{~mol} \%), 110^{\circ} \mathrm{C}, \mathrm{CO}_{2}$ (10 bar).

\section{Conclusions}

Three $\mathrm{N}_{4}$-chelated $\mathrm{Zn}$ complexes based on the tris(2-aminoethyl)amine (tren) scaffold were synthesized and successfully tested as catalysts in the coupling of $\mathrm{CO}_{2}$ with epoxides to produce cyclic carbonates. Under the optimized reaction conditions $\left(110^{\circ} \mathrm{C}, 10\right.$ bar $\left.\mathrm{CO}_{2}, 3 \mathrm{~h}\right)$, all three tripodal $\mathrm{Zn}$-azatrane complexes associated with a $n \mathrm{Bu}_{4} \mathrm{Nl}$ co-catalyst exhibited good to high activity within this short reaction timeframe with yields and turnover numbers (TONs) up to $79 \%$ and 316 , respectively. Performing the reactions at a low catalyst loading $(0.005 \mathrm{~mol} \%)$ or at room temperature evidenced that less sterically hindered methyl-substituted $\mathbf{Z n}$ "-azatrane $\mathbf{2 a}$ was the most efficient catalyst of the series, highlighting the importance of the accessibility of the Lewis acid site to synergistically activate the epoxide. With binary catalyst system $2 \mathrm{a} / \mathrm{nBu}_{4} \mathrm{NI}$, TONs as high as 11200 could be achieved, an activity far superior to that reported for other $\mathrm{N}_{4}$-chelated $\mathrm{Zn}$ complexes (i.e., $\mathrm{Zn}$-pyrrolidine-based catalyst). We also showed that $2 \mathrm{a} / n \mathrm{nu}_{4} \mathrm{NI}$ could be applied to a wide range of epoxide substrates, converting terminal epoxides into their corresponding carbonates in high yields (75 to $95 \%$ ) in only $3 \mathrm{~h}$, whereas a longer reaction period $(24 \mathrm{~h})$ was required in the case of internal and more sterically congested epoxides to attain satisfactory conversion (27 to $67 \%$ ). Finally, the $\mathrm{Zn}$-azatrane complexes could be reused up to three times without any substantial loss in activity, underlining their robustness under the reaction conditions. Current work concentrates on optimizing the design of solid catalysts derived from the Zn-azatrane motif towards higher recycling capacities and on the introduction of chirality to develop high-value added enantioselective pathways by using $\mathrm{CO}_{2}$ as a raw reagent.

\section{Experimental Section}

\section{General}

The commercial reagents $\mathrm{Zn}\left(\mathrm{ClO}_{4}\right)_{2} \cdot 6 \mathrm{H}_{2} \mathrm{O}$ and tren (1 a) were purchased from Aldrich Chemicals and were used without further purification. Solvents were dried by using standard methods and were stored over activated $4 \AA$ molecular sieves. Depending on the experiments, ${ }^{1} \mathrm{H}$ NMR and ${ }^{13} \mathrm{C}$ NMR spectra were recorded with a Bruker Avance 300 spectrometer at 300.1 and $75.48 \mathrm{MHz}$, respectively, or a Bruker Avance HD III 400 spectrometer at 400.1 and 100.6 MHz, respectively. Chemical shifts were referenced to tetramethylsilane. Mass spectral analyses were performed with a Nermag R10-10C for exact mass. Compounds $\mathbf{1} \mathbf{b}$ and $\mathbf{1} \mathbf{c}$ were synthetized according to literature procedures. ${ }^{[4]]}$

\section{Synthesis and characterization of $\mathrm{Zn}^{\text {"I}}$-azatrane complexes $2 a-c$}

In a Schlenk flask, equimolar amounts of tren ligands $\mathbf{1} \mathrm{a}-\mathrm{c}$ and $\mathrm{Zn}\left(\mathrm{ClO}_{4}\right)_{2} \cdot 6 \mathrm{H}_{2} \mathrm{O}$ were solubilized in methanol $(1 \mathrm{~mL})$ and stirred for $1.5 \mathrm{~h}$ at room temperature. After the evaporation of methanol, obtained complexes $\mathbf{2} \mathbf{a}-\mathbf{c}$ were washed with small portions of diethyl ether, resolubilized in acetonitrile, and reprecipitated by the dropwise addition of diethyl ether. Complexes $\mathbf{2 a - c}$ were obtained as crystalline powders and dried under vacuum at room temperature.

2 a: Yield: $78 \%$; ${ }^{1} \mathrm{H}$ NMR $\left(300.1 \mathrm{MHz}, \mathrm{CD}_{3} \mathrm{OD}, 298 \mathrm{~K}\right): \delta=2.52(\mathrm{~m}$, $4 \mathrm{H}), 2.34(\mathrm{~s}, 3 \mathrm{H}), 1.92 \mathrm{ppm}(\mathrm{m}, 1 \mathrm{H}) ;{ }^{13} \mathrm{C}$ NMR $\left(100.6 \mathrm{MHz}, \mathrm{CD}_{3} \mathrm{OD}\right.$, $298 \mathrm{~K}): \delta=32.34,46.55,50.39 \mathrm{ppm}$; HRMS (ESI): $\mathrm{m} / \mathrm{z}$ : calcd for $\mathrm{C}_{9} \mathrm{H}_{24} \mathrm{ClN}_{4} \mathrm{Zn}: 287.0975\left[\mathrm{M}-2 \mathrm{ClO}_{4}+\mathrm{Cl}^{+}\right.$; found: 287.0975 .

2 b: Yield: $72 \%$; ${ }^{1} \mathrm{H}$ NMR $\left(300.1 \mathrm{MHz}, \mathrm{CDCl}_{3}, 298 \mathrm{~K}\right): \delta=1.70-2.07$ $(\mathrm{m}, 2 \mathrm{H}), 2.57-2.78(\mathrm{~m}, 2 \mathrm{H}), 3.68(\mathrm{~s}, 3 \mathrm{H}), 6.56(\mathrm{~m}, 2 \mathrm{H}), 7.29 \mathrm{ppm}(\mathrm{m}$, $2 \mathrm{H}) ;{ }^{13} \mathrm{C}$ NMR $\left(100.6 \mathrm{MHz}, \mathrm{CD}_{3} \mathrm{CN}, 298 \mathrm{~K}\right): \delta=53.18,47.90,51.57$, 54.39, 113.92, 130.46, 130.75, 159.95 ppm; HRMS (ESI): $\mathrm{m} / \mathrm{z}$ : calcd for $\mathrm{C}_{30} \mathrm{H}_{42} \mathrm{ClN}_{4} \mathrm{O}_{3} \mathrm{Zn}: 605.2231\left[\mathrm{M}-2 \mathrm{ClO}_{4}+\mathrm{Cl}\right]^{+}$; found: 605.2227 .

2 c: Yield: $65 \%$; ${ }^{1} \mathrm{H}$ NMR (300.1 MHz, $\left.\mathrm{CD}_{3} \mathrm{OD}, 298 \mathrm{~K}\right): \delta=1.10(\mathrm{~s}, 9 \mathrm{H})$, $2.78(\mathrm{~s}, 2 \mathrm{H}), 2.90(\mathrm{t}, 2 \mathrm{H}), \quad 3.07-3.21 \mathrm{ppm}(\mathrm{m}, 2 \mathrm{H}) ;{ }^{13} \mathrm{C} N \mathrm{NMR}$ $\left(100.6 \mathrm{MHz}, \quad \mathrm{CD}_{3} \mathrm{CN}, \quad 298 \mathrm{~K}\right): \delta=27.09, \quad 32.66,46.18, \quad 49.63$, $59.71 \mathrm{ppm}$; HRMS (ESI): $\mathrm{m} / \mathrm{z}$ calcd for $\mathrm{C}_{21} \mathrm{H}_{48} \mathrm{CIN}_{4} \mathrm{Zn}: 455.2890$ $\left[\mathrm{M}-2 \mathrm{ClO}_{4}+\mathrm{Cl}\right]^{+}$; found: 455.2853 .

\section{Catalytic procedure}

In a typical experiment, 1,2-epoxyhexane (10.0 mmol), $\mathrm{Zn}$ "-azatrane complex $2(0.25 \mathrm{~mol} \%)$, and $n \mathrm{Bu}_{4} \mathrm{NX}(\mathrm{X}=\mathrm{Cl}, \mathrm{Br}, \mathrm{l} ; 0.40 \mathrm{~mol} \%)$ were loaded into a $25 \mathrm{~mL}$ stainless autoclave. The reactor was flushed $(3 \times)$ at room temperature with $\mathrm{CO}_{2}(99.99 \%, 5$ bar) to remove air from the vessel before it was charged to 10 bar of $\mathrm{CO}_{2}$ and the temperature was raised to $110^{\circ} \mathrm{C}$. After the desired reaction time, the reactor was cooled with an ice bath to stop the reaction, and finally, the excess amount of $\mathrm{CO}_{2}$ was carefully released. The crude mixture was analyzed by ${ }^{1} \mathrm{H}$ NMR spectroscopy by using mesitylene as an internal standard. A typical ${ }^{1} \mathrm{H}$ NMR spectrum of the crude reaction mixture is provided in the Supporting Information (Figure $\mathrm{S} 2$ ).

\section{Recycling procedure}

In the recycling experiment, used catalyst $\mathbf{2} \mathbf{a}$ or $\mathbf{2} \mathbf{b}$ was fully recovered from the reaction mixture by precipitation with diethyl ether. After separation by filtration and careful washing with dieth$y l$ ether $(3 \times 2 \mathrm{~mL})$, the spent catalyst was dried at $50^{\circ} \mathrm{C}$ overnight in an oven and then reused for another run, maintaining the molar ratio of epoxide and the $n \mathrm{Bu}_{4} \mathrm{Nl}$ co-catalyst as described above for a typical test. 


\section{Acknowledgements}

The authors gratefully acknowledge the Agence Nationale de la Recherche (https://doi.org/10.13039/501100001665), Project: AZAP-CO2 N $N^{\circ}$ ANR-14-CE06-0018-01, for funding.

[1] M. Stradiotto, R. J. Lundgren, Ligand Design in Metal Chemistry: Reactivity and Catalysis, Wiley, Chichester, 2016.

[2] T. P. Yoon, E. N. Jacobsen, Science 2003, 299, 1691-1693.

[3] Q.-L. Zhou, Privileged Chiral Ligands and Catalysts, Wiley-VCH, Weinheim, 2011.

[4] P. G. Cozzi, Chem. Soc. Rev. 2004, 33, 410-421.

[5] K. C. Gupta, A. K. Sutar, Coord. Chem. Rev. 2008, 252, 1420-1450.

[6] B. Meunier, Chem. Rev. 1992, 92, 1411-1456.

[7] E. Rose, B. Andrioletti, S. Zrig, M. Quelquejeu-Ethève, Chem. Soc. Rev. 2005, 34, 573-583.

[8] J. F. Teichert, B. L. Feringa, Angew. Chem. Int. Ed. 2010, 49, 2486-2528; Angew. Chem. 2010, 122, 2538-2582.

[9] H. Büttner, L. Longwitz, J. Steinbauer, C. Wulf, T. Werner, Top. Curr. Chem. 2017, 375, 1-56.

[10] T. Sakakura, J. C. Choi, H. Yasuda, Chem. Rev. 2007, 107, 2365-2385.

[11] P. Pescarmona, M. Taherimehr, Catal. Sci. Technol. 2012, 2, 2169-2187.

[12] P. Anastas, N. Eghbali, Chem. Soc. Rev. 2010, 39, $301-312$.

[13] M. Aresta, A. Dibenedetto, A. Angelini, Chem. Rev. 2014, 114, 17091742.

[14] Q. Liu, L. Wu, R. Jackstell, M. Beller, Nat. Commun. 2015, 6, 5933-6933.

[15] C. Martín, C. J. Whiteoak, E. Martin, M. M. Belmonte, E. C. EscuderoAdán, A. W. Kleij, Catal. Sci. Technol. 2014, 4, 1615-1621.

[16] W.-M. Ren, Y. Liu, X.-B. Lu, J. Org. Chem. 2014, 79, 9771-9777.

[17] A. Coletti, C. J. Whiteoak, V. Conte, A. W. Kleij, ChemCatChem 2012, 4, $1190-1196$.

[18] J. A. Castro-Osma, K. J. Lamb, M. North, ACS Catal. 2016, 6, 5012-5025.

[19] N. Takeda, S. Inoue, Makromol. Chem. 1978, 179, 1377-1381.

[20] T. Ema, Y. Miyazaki, S. Koyama, Y. Yano, T. Sakai, Chem. Commun. 2012, 48, 4489-4491.

[21] T. Ema, Y. Miyazaki, J. Shimonishi, C. Maeda, J.-Y. Hasegawa, J. Am. Chem. Soc. 2014, 136, 15270-15279.

[22] C. Maeda, T. Taniguchi, K. Ogawa, T. Ema, Angew. Chem. Int. Ed. 2015 54, 134-138; Angew. Chem. 2015, 127, 136-140.
[23] J. E. Dengler, M. W. Lehenmeier, S. Klaus, C. W. Anderson, E. Herdtweck, B. Rieger, Eur. J. Inorg. Chem. 2011, 336-343.

[24] L. Cuesta-Aluja, M. Djoufak, A. Aghmiz, R. Rivas, L. Christ, A. M. MasdeuBultó, J. Mol. Catal. A 2014, 381, 161-170.

[25] C. T. Cohen, T. Chu, G. W. Coates, J. Am. Chem. Soc. 2005, 127, 1086910878.

[26] A. Decortes, M. M. Belmonte, J. Benet-Buchholza, A. W. Kleij, Chem. Commun. 2010, 46, 4580-4582.

[27] A. Decortes, A. W. Kleij, ChemCatChem 2011, 3, 831-834.

[28] M. A. Fuchs, S. Staudt, C. Altesleben, O. Walter, T. A. Zevaco, E. Dinjus, Dalton Trans. 2014, 43, 2344-2347.

[29] D. J. Darensbourg, J. R. Wildeson, J. C. Yarbrough, J. H. Reibenspies, J. Am. Chem. Soc. 2000, 122, 12487-12496.

[30] M. R. Kember, P. D. Knight, P. T. R. Reung, C. K. Williams, Angew. Chem. Int. Ed. 2009, 48, 931-933; Angew. Chem. 2009, 121, 949-951.

[31] J. Meléndez, M. North, R. Pasquale, Eur. J. Inorg. Chem. 2007, $3323-$ 3326.

[32] M. North, R. Pasquale, Angew. Chem. Int. Ed. 2009, 48, 2946-2948; Angew. Chem. 2009, 121, 2990-2992.

[33] M. North, P. Villuendas, C. Young, Chem. Eur. J. 2009, 15, 11454-11457.

[34] J. Whiteoak, N. Kielland, V. Laserna, E. C. Escudero-Adán, E. Martin, A. W. Kleij, J. Am. Chem. Soc. 2013, 135, 1228-1231.

[35] C. Miceli, J. Rintjema, E. Martin, E. C. Escudero-Adán, C. Zonta, G. Licini, A. W. Kleij, ACS Catal. 2017, 7, 2367-2373.

[36] J. G. Verkade, Coord. Chem. Rev. 1994, 137, 233- 295.

[37] R. R. Schrock, Acc. Chem. Res. 1997, 30, 9-16.

[38] B. Chatelet, L. Joucla, J.-P. Dutasta, A. Martinez, K. C. Szeto, V. Dufaud, J. Am. Chem. Soc. 2013, 135, 5348-5351.

[39] B. Chatelet, E. Jeanneau, J.-P. Dutasta, V. Robert, A. Martinez, V. Dufaud, Catal. Commun. 2014, 52, 26-30.

[40] B. Chatelet, L. Joucla, J.-P. Dutasta, A. Martinez, V. Dufaud, Chem. Eur. J. 2014, 20, $8571-8574$.

[41] S. He, F. Wang, W.-L. Tong, S.-M. Yiu, M. C. W. Chan, Chem. Commun. 2016, 52, 1017- 1020.

[42] M. Adolph, T. A. Zevaco, C. Altesleben, S. Staudt, E. Dinjus, J. Mol. Catal. A 2015, 400, 104-110.

[43] E. Mercadé, E. Zangrando, C. Claver, C. Godard, ChemCatChem 2016, 8, $234-243$.

[44] F. Ono, K. Qiao, D. Tomida, C. Yokoyama, J. Mol. Catal. A 2007, 263, $223-226$

[45] A. I. Elkurtehi, F. M. Kerton, ChemSusChem 2017, 10, 1249-1254.

[46] L. Martínez-Rodríguez, J. Otalora Garmilla, A. W. Kleij, ChemSusChem 2016, 9, 749-755

[47] P. B. Kisanga, J. G. Verkade, Tetrahedron 2001, 57, 467-475. 